\title{
Conservation Biocontrol in Fragmented Landscapes: Persistence and Parasitation in a Host-Parasitoid Model
}

\author{
Ute Visser $^{1,2}$, Kerstin Wiegand $^{2,3, \#}$, Volker Grimm ${ }^{1}$ and Karin Johst ${ }^{* 1}$ \\ ${ }^{I}$ UFZ, Helmholtz Centre for Environmental Research - UFZ, Department of Ecological Modelling, Germany \\ ${ }^{2}$ Interdisciplinary Research Centre for Environmental Protection (IFZ), Biometry and Population Genetics, Giessen, \\ Germany \\ ${ }^{3}$ Friedrich-Schiller-University, Institute of Ecology, Jena, Germany
}

\begin{abstract}
In the context of agricultural landscapes, conservation biocontrol practitioners attempt to secure and enhance the presence and effectiveness of natural enemies of insect pest species, for example parasitoids. Conservation biocontrol aims at maximizing both parasitoid persistence and parasitation rate. It is, however, still poorly understood how the amount, fragmentation and isolation of non-crop habitat of the host and its parasitoid affect persistence and parasitation rate. We developed a spatially explicit simulation model of a host and its specialized parasitoid and simulated their spatiotemporal population dynamics in virtual landscapes. We found that the total habitat amount in the landscape modulates the impact of fragmentation on parasitoid persistence. If habitat is abundant, parasitoid persistence decreases with fragmentation, whereas if habitat is scarce, persistence is highest at intermediate levels of fragmentation. In any case, persistence is best for intermediate levels of isolation. Parasitation rate, on the other hand, is negatively influenced by fragmentation and isolation regardless of the habitat amount. Our results suggest that in landscapes with abundant habitat, both parasitation rates and parasitoid persistence can be increased by arranging habitat to be as clumped as possible. However, if habitat is scarce, landscape management can optimize either parasitation rates or parasitoid persistence but not both simultaneously.
\end{abstract}

Keywords: Heterogeneous landscape, agricultural landscape, habitat isolation, fragmentation, parasitoids, insect pest species, parasitation rate, parasitoid persistence, conservation biological control, landscape management.

\section{INTRODUCTION}

In agricultural landscapes, insect pest populations may be controlled by promoting their natural enemies, for example by providing set-asides and other semi-natural habitat, a practice termed conservation biological control (or "conservation biocontrol"(Barbosa 1998; Landis, Wratten \& Gurr 2000)). Host-parasitoid interactions are of particular interest for conservation biocontrol because parasitoids, whether introduced or autochthonous, have the potential to regulate economically important host populations (Beddington, Free \& Lawton 1978; Hawkins \& Cornell 1994; Thies \& Tscharntke 1999; Cardinale et al. 2003).

Recent field observations suggest that the control of insect pest populations through natural parasitoids depends on the structure of the surrounding landscape (Kruess \& Tscharntke 1994; Thies \& Tscharntke 1999). Hence, for successful control, a good understanding of the role of land-

\footnotetext{
*Address for correspondence to this author at the Helmholtz-Zentrum für Umweltforschung - UFZ, Department Ökologische Systemanalyse, Permoserstr. 15, 04318 Leipzig, Germany; Tel: ++49-(0)341- 2351709; Fax: ++49-(0)341-2351473; E-mail: karin.johst@ufz.de

"Present address: Ecosystem Modelling, Georg-August-University, Göttingen, Germany Handling editor: Prof. Boris Krasnov
}

scape structure is needed, especially because agricultural landscapes are undergoing major changes resulting in habitat loss, fragmentation and isolation (Sala et al. 2000). These changes in landscape structure are known to impact the dynamics of both individual species (Bascompte, Possingham \& Roughgarden 2002; Wiegand, Revilla \& Moloney 2005) and species interactions (Moilanen \& Hanski 1995; Tilman, Lehman \& Yin 1997). Thus, design and management of landscape structure could be used to enhance biocontrol (Tscharntke et al. 2005).

However, despite the accumulated general knowledge on the role of landscape structure on predator-prey interactions (Ryall and Fahrig 2006), the mechanisms controlling the success or failure of conservation biocontrol in a given landscape are still poorly understood. In part, this is because of difficulties in empirically investigating biocontrol at the landscape scale. Most of the potentially important factors are either hard to assess (e.g. large-scale spatiotemporal insect population dynamics) or difficult to separate (e.g. strongly correlated aspects of landscape structure such as habitat amount and inter-patch distance). Consequently, there is limited knowledge on the causal link between landscape features and population dynamics of interacting species (Cronin \& Reeve 2005) and on how to enhance conservation biocontrol by managing agricultural landscape structure. 
We therefore developed a spatially explicit model of a host and its specialized parasitoid. We focus on two measures that are widely used to assess the performance of biocontrol: persistence, which quantifies the parasitoid's reliability, and parasitation rate, which quantifies the parasitoid's effectiveness. The first measure is commonly used in theoretical studies and the latter in field studies. We created virtual landscapes consisting of a matrix that was unsuitable for host and parasitoid, together with patches of non-crop host habitat of varying number, size, and spatial distribution. We thus independently manipulated the amount, fragmentation, and isolation of the host habitat, thereby covering a wide range of landscape structures and habitat amounts. The model describes hypothetical species, but was designed to address conservation biocontrol of the rape pollen beetle system (Meligethes aeneus (Fabricius)) which is highly relevant for many agricultural landscapes in Europe.

The importance of spatial heterogeneity for hostparasitoid interactions has been recognized since the classical experiments of Huffaker (1958). It has been a wellestablished opinion that spatial heterogeneity - often interpreted as a synonym of fragmentation - in general tends to be favorable for biological control because heterogeneity stabilizes oscillatory behavior and thus can increase the persistence of predator-prey or host-parasitoid interactions, or disease dynamics (De Roos, McCauly \& Wilson 1991; Bolker \& Grenfell 1995; Bonsall, French \& Hassell 2002). According to modelling studies of Beddington (1978), spatial heterogeneity provides the most promising mechanism for high host suppression. However, there are empirical (Kareiva 1987; With et al. 2002) and modeling (Hassell, Godfray \& Comins 1993) experiments suggesting that habitat fragmentation may cause prolonged host outbreaks and increased parasitoid extinction risk, contradicting the stabilizing role of spatial heterogeneity.

It has often been argued that negative effects of landscape fragmentation on host-parasitoid or predator-prey interactions can originate in: (1) the limited dispersal ability of the parasitoid (Tscharntke et al. 2005), or (2) the specific searching behavior (active interaction of the organism with landscape features) of the predator (With et al. 2002). On the other hand, there are hints suggesting that there might be a fundamental effect of landscape fragmentation on biocontrol, as in the case of the rape pollen beetle and its specialized parasitoids; which is a system showing pronounced effects of landscape structure on biocontrol (Kruess \& Tscharntke 1994; Thies \& Tscharntke 1999), despite the fact that herbivory and parasitation react to landscape features at the same spatial scale (Thies, Steffan-Dewenter \& Tscharntke 2003).

The performance of biocontrol could possibly be explained by various landscape features such as proportion of habitat, landscape complexity (Thies \& Tscharntke 1999), fragmentation (Kareiva 1987), and isolation (Kruess \& Tscharntke 1994). However, interpretation of these results is difficult because some of the landscape measures are correlated and therefore the underlying mechanisms are hard to identify. Thus, despite the existing theoretical knowledge on spatial host-parasitoid and predator-prey interactions concerning the effects of dispersal rates, aggregation, and attack rates on stability, persistence, and abundance (Holyoak \& Lawler 1996; Hassell 2000), there is little knowledge on the effect of landscape structure and composition on biocontrol (Hirzel, Nisbet \& Murdoch. 2007). Theoreticians sometimes feel that theoretical results and concepts are ignored by empiricists (Ryall \& Fahrig 2006) but apparently there is a need for theoretical studies which directly address biocontrol measures and landscape features relevant to managers.

\section{METHODS}

We built a spatially explicit grid-based model, in which space is represented in the form of discrete cells. As our reference for model parameterization, we chose the rape pollen beetle and its specific parasitoids in semi-natural habitat (Fritzsche 1956; Hokkanen, Husberg \& Söderblom 1988; Daebeler, Seidel \& Michel 1990; Börjesdotter 2000; Hokkanen 2000). One grid cell in the model represents a 100 $\mathrm{m} \times 100 \mathrm{~m}$ area of an agricultural landscape which can be either suitable "habitat" for the host (e.g. set asides) or unsuitable "matrix" (e.g. other crops, but not rape). Each cell can contain a subpopulation of host and parasitoid and is the place for the local processes reproduction, parasitation, and mortality. Local subpopulations are linked by dispersing host and parasitoid individuals.

Both host and parasitoid reproduce once a year with nonoverlapping generations. Reproduction, parasitation, mortality, and dispersal are calculated in annual time steps. We assumed that host reproduction is density-dependent and that density dependence acts before parasitation (Nilsson 1989). We modeled the female hosts only, which means that in the model one individual can start the growth of a population without reproduction partner. We use the Rickerfunction (Bellows 1981) to describe population dynamics of the host:

$$
N_{t+1}=N_{t} \cdot R_{H} \cdot \exp \left(-\operatorname{In}\left(R_{H}\right) \frac{N_{t}}{K_{H}}\right)
$$

with $N_{t}$ being the number of hosts in the cell at time $t, K_{H}$ the local maximum capacity, and $R_{H}$ the maximal reproduction rate (see Table 1).

Based on the assumption that the size of a habitat cell corresponds to the size of the searching range of a parasitoid, in our model the distribution of parasitoid eggs on hosts is random and limited by parasitoid fecundity. Thus, the probability that hosts escape parasitation is determined by the zero-term of the Poisson-distribution, and the number of parasitoids hatching in the next time step is then given by

$$
P_{t+1}=N_{t} \cdot\left(1-\exp \left(-R_{P} \cdot \frac{P_{t}}{N_{t}}\right)\right)
$$

Here $P_{t}$ and $N_{t}$ are the population size of the parasitoid and the host at time $\mathrm{t}$ described by whole numbers and $R_{P}$ is the maximum number of eggs per parasitoid (see Table 1). In analogy to the hosts, we modeled female parasitoids only (with sex ratio 1:1). Eqs. (1) and (2) are deterministic and extinction occurs at zero population size. Including demographic stochasticity explicitly would require much 
Table 1. Model Parameters and their Reference Values

\begin{tabular}{|c|c|c|c|}
\hline Parameter & Meaning & Reference Value & Unit \\
\hline \hline$K_{H}$ & $\begin{array}{c}\text { Local (=within cell) maximum } \\
\text { capacity of hosts }\end{array}$ & 500 & individuals/cell $^{1}$ \\
\hline$R_{H}$ & Host's maximum reproduction rate & 2.2 & - \\
\hline$R_{P}$ & $\begin{array}{c}\text { Maximum number of eggs per } \\
\text { parasitoid }\end{array}$ & 5 & 5 \\
\hline$D_{H}$ & Host's mean dispersal distance & 5 & Cells \\
\hline$D_{P}$ & Parasitoid's mean dispersal distance & Cells \\
\hline
\end{tabular}

${ }^{1}$ One cell represents $100 \mathrm{~m} \times 100 \mathrm{~m}$.

more computation time but had only negligible effects on the results.

We assumed that host and parasitoid have the same dispersal behavior. Dispersing individuals fly in a randomly chosen direction and settle after covering a distance randomly chosen from a negative exponential distribution. The distribution is characterized by a mean dispersal distance $D_{H}$ and $D_{P}$ common to host and parasitoid. To estimate the mean dispersal distance (Table 1), we assumed that only a small proportion of a population $(0.001 \%)$ may be able to fly very far $(6 \mathrm{~km}$, the furthest distance reported in the literature (Daebeler et al. 1990)). We did not include any movement response to the landscape structure.

Host and parasitoid are univoltine, which means that they live for one year and die after reproduction. Host and parasitoid individuals die when random dispersal ends in a matrix cell and host individuals die when being parasitized.

The annual schedule of processes of the model is as follows. First, hosts die due to parasitation. The remaining host and parasitoid individuals then disperse. If a host individual ends up in a habitat cell, it reproduces according to the density-dependent reproduction function (Eq. 1) and dies afterwards. The offspring of the host can then be parasitized (Eq. 2) by egg-laying parasitoids in the same cell. At this point the data for the analysis are recorded. All parasitized hosts die after producing one new parasitoid each.

A habitat patch is defined as a continuous area of habitat. In our model the size of a habitat patch is defined by the total number of habitat cells that are connected with each other via at least one of their eight neighboring cells. In a first set of landscape scenarios, we varied the size of one single square-shaped habitat patch in six steps and determined the persistence of the parasitoid population as a function of the total amount of habitat. From these single-patch scenarios we then chose one scenario with a relatively low persistence of parasitoid populations as a starting point for a second set of landscape scenarios.

In this second set of landscape scenarios, we manipulated habitat fragmentation by dividing a given amount of habitat into a number of equal-sized smaller patches. In a scenario with a low amount of habitat (2500 habitat cells) we varied the number and the size of the square-shaped patches by systematically dividing the original $50 \times 50$ cell patch into several smaller squares of equal size resulting in fragmentation levels of $1,4,25$, and 100 patches, consisting of $2500,625,100$, and 25 cells, respectively. For the scenario with a high amount of habitat (4900 habitat cells) we proceeded similarly, resulting in 1, 4, 49 and 196 patches consisting of 4900, 1225, 100 and 25 cells, respectively. Additionally, for each fragmentation level we manipulated

Table 2. Parameter Range and Examples for the Landscape Scenario Analyzed

\begin{tabular}{|c|c|c|c|}
\hline & Number of Patches & Patch Size (cells) ${ }^{1}$ & Patch Isolation (cells) $^{2}$ \\
\hline Scenario 1 & 1 & $100-10000$ & \\
\hline \multicolumn{4}{|l|}{ Example scenario $1^{3}$} \\
\hline $\begin{array}{l}\text { Scenario } 2 \\
\text { a) low amount of habitat } \\
\text { b) high amount of habitat }\end{array}$ & $\begin{array}{l}\text { a) } 1-100 \\
\text { b) } 1-196\end{array}$ & $\begin{array}{l}\text { a) } 2500-25 \\
\text { b) } 4900-25\end{array}$ & $\begin{array}{l}\text { a) } 5-30 \\
\text { b) } 5-30\end{array}$ \\
\hline Example scenario 2 & & & \\
\hline
\end{tabular}

\footnotetext{
${ }^{1}$ Patch size describes the patch area.

${ }^{2}$ Patch isolation is the shortest distance between nearest neighbor-patches.

${ }^{3}$ Dark gray: matrix, light gray: habitat.
} 
isolation by varying the shortest distance between the neighboring patches to be $5,10,20$ or 30 cells. This led to 16 different landscapes for each of the above two scenarios. The grid size is adjusted to encompass both habitat patches and isolating matrix; the boundary conditions are absorbing. For the parameter range and examples of both sets of scenarios see Table 2 .

Each simulation run was started by defining a landscape pattern according to the landscape scenarios described above. In the new landscape, host and parasitoid populations were initialized by providing $0.2 \%$ of the grid cells with a host and a parasitoid subpopulation of the size of $K_{H}$ and $K_{H} / 2$, respectively. One simulation run consisted of 600 time steps. In order to be independent of the initial conditions, we analyzed data from time step 201 to time step 600. We ran 100 replicates for each landscape scenario and determined the persistence of the parasitoid population. We estimated the persistence of the parasitoid population at the landscape level, by calculating the proportion of simulation runs out of 100 in which the parasitoid population survived for at least 600 years.

If persistence was greater than zero, the first 10 replicates with persistent parasitoid populations were used for further analyses. To determine parasitation rate, we calculated the ratio of parasitoids to hosts in each cell after reproduction of host and parasitoid and before the parasitized hosts died. The parasitation rate is the average parasitoid-to-host ratio, calculated from the total numbers of parasitoids and hosts over the last 400 time steps. Finally, at the end of the simulation, we calculated the arithmetic mean and the standard deviation of ten replicates.

To quantify outbreaks, we observed population dynamics on an exemplary cell in the center of a habitat patch. For each outbreak, we measured the number of consecutive time steps during which a host population was present. Because within this cell and within the simulation period of 400 time steps, several outbreaks were possible, we calculated the duration of host outbreaks by averaging over all outbreaks within the 10 replicates.

\section{RESULTS}

The interaction of host and parasitoid in the simulation model is locally unstable and exhibits oscillatory behavior in time (Fig. 1). When there are no parasitoids in the cell, the host population size increases until the population size reaches the carrying capacity. When a parasitoid reaches a

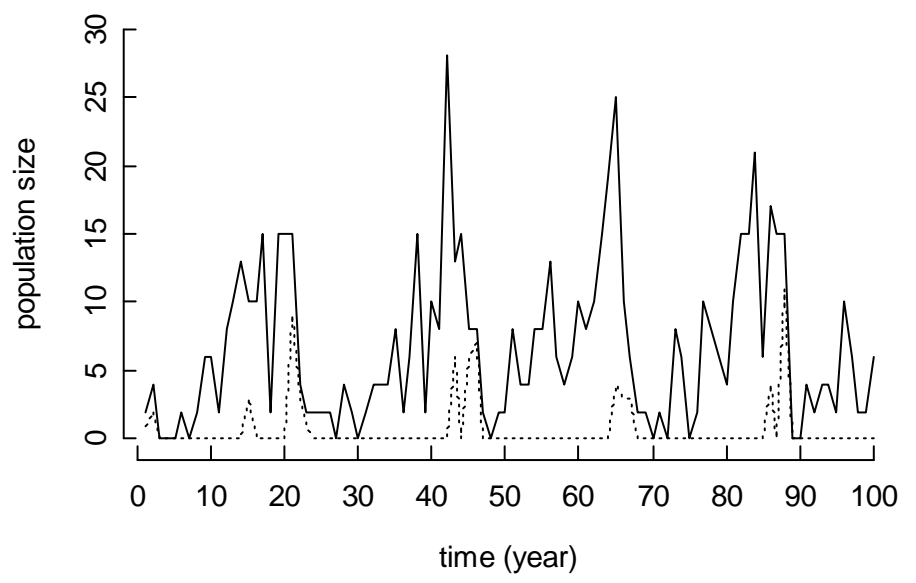

Fig. (1). Population density of adult hosts (black line) and parasitoid larvae (dotted line) oscillating with time in one exemplary cell; simulation run with standard parameter set (Table 1) and landscape parameters as visualized in Fig. (2): habitat amount 2500 cells, number of patches 25 , patch distance 10 cells.

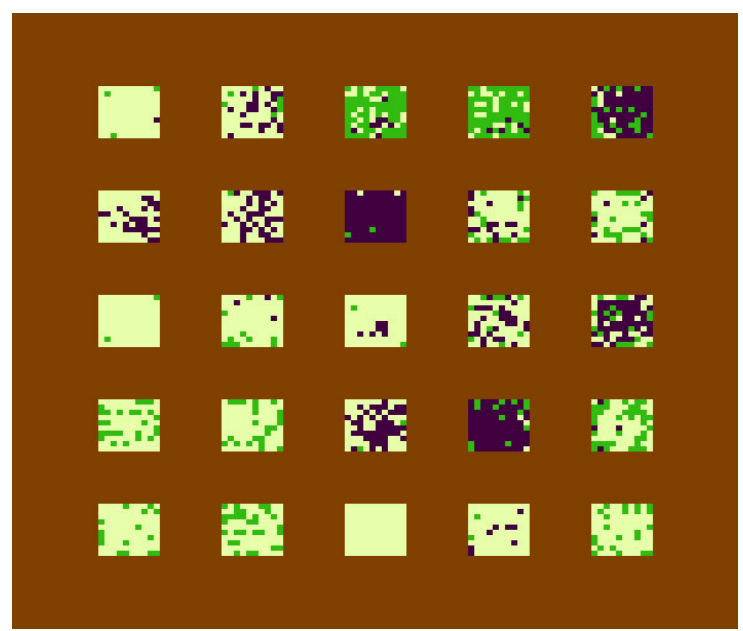

Fig. (2). Snapshot of a virtual landscape of the scenario with low amount of habitat (habitat amount 2500 cells, number of patches 25 , patch distance 10 cells) during a simulation run; white: cells with only host population, dark pink: cells with host and parasitoid population, brown: matrix cells, green: empty habitat cells. 


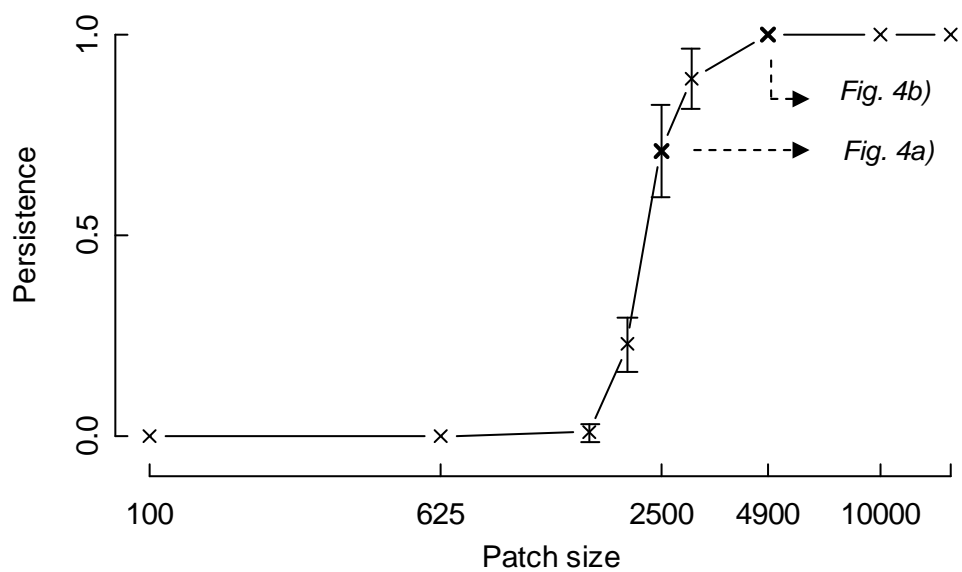

Fig. (3). Persistence of parasitoids in a single patch increases with patch size; from the single-patch landscapes we chose one with low persistence (2500 cells, Fig. (4a)) and one with high persistence (4900 cells, Fig. (4b)), which we then used for the fragmentation experiment); error bars show the standard deviation for ten simulation runs.

host population, the parasitoid reproduces by parasitizing the hosts, thereby causing a reduction of host population size. Generally, these local oscillations of host and parasitoid densities lead to a wave-like or chaotic spatial pattern (Fig. 2) with increasing local host populations at the wave front, followed by increasing parasitoid populations (see also Hirzel et al. 2007). These waves of hosts and parasitoids move across the landscape with time (Supplementary 1). As the parasitoid populations cause the local extinction of host, they leave a zone of empty cells behind. Parasitoids and their hosts are thought to be predisposed to locally unstable dynamics (e.g. Bonsall et al. 2002) and traveling waves have been empirically confirmed in a number of host-parasitoid systems (e.g. Eber \& Brandl 1994; Blasius, Huppert \& Stone 1999; Sherratt, Lambin \& Sherratt 2003).

Persistence of parasitoids increases with increasing single patch size, exhibiting threshold behavior (first set of landscape scenarios, Fig. 3).

Given a low amount of habitat, the persistence of the parasitoid population is highest at intermediate fragmentation levels (Fig. 4a). Similarly, for a given fragmentation,

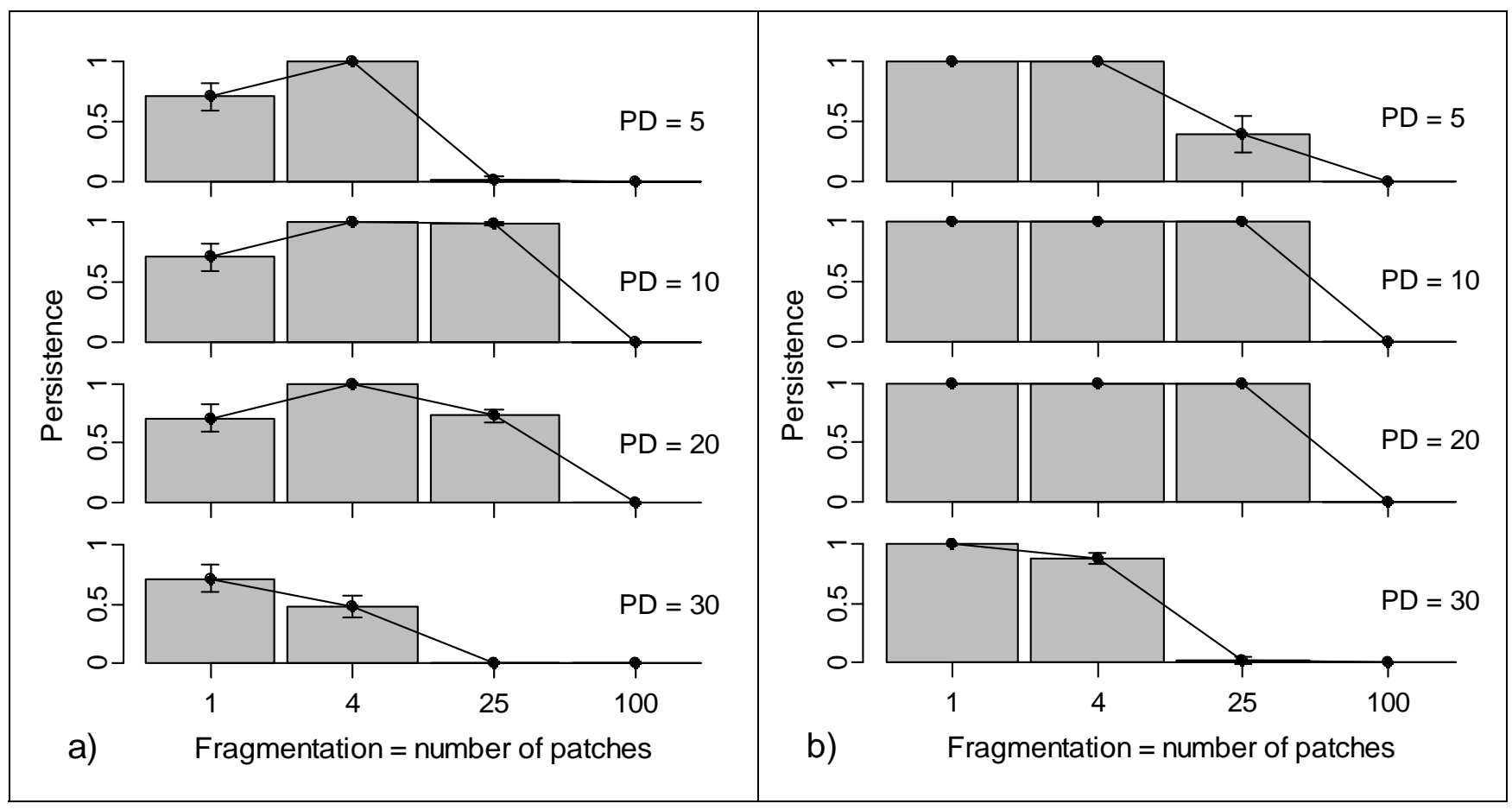

Fig. (4). We fragmented a single square-shaped patch with low persistence (low amount of habitat) and a big single patch with high persistence (high amount of habitat) stepwise into a number of square shaped fragments of accordingly smaller patch sizes: a) for a low amount of habitat, persistence of the parasitoids in the landscape is highest for intermediate patch numbers; b) for a high amount of habitat, persistence is highest for low patch numbers. For both scenarios persistence is best at intermediate patch distances (PD); error bars show the standard deviation for ten simulation runs. 


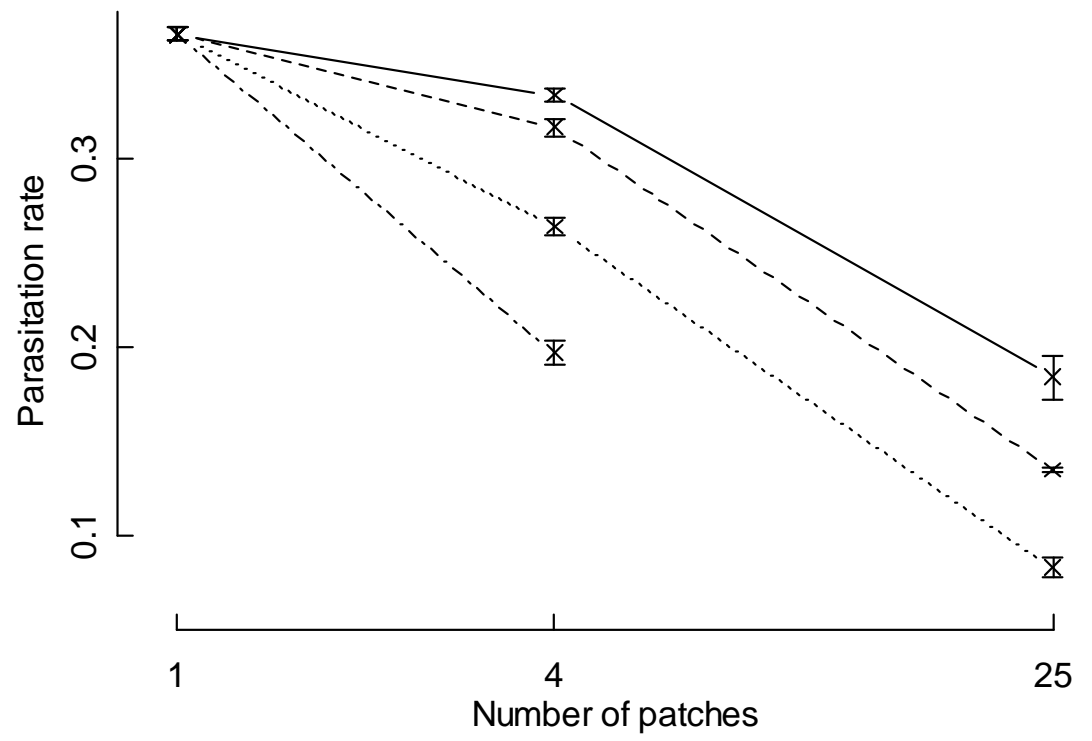

Fig. (5). Parasitation rates decrease with the number of patches and decrease with patch distance in both habitat amount scenarios (exemplified here for low habitat amount). Solid line: patch distance $=5$ cells; dashed line: patch distance $=10$ cells; dotted line: patch distance $=20$ cells; dashed-dotted line: patch distance $=30$ cells; error bars show the standard deviation for ten simulation runs.

persistence is highest at intermediate levels of isolation, i.e., patch distances (Fig. 4a). Note that this peak in persistence appears only under parameterizations that exhibit low persistence in unfragmented landscapes (scenario with low amount of habitat) (Fig. 4a) and if isolation is not too high (patch distance $=30$ in Fig. 4a). Parameterizations exhibiting high persistence in unfragmented landscapes (scenario with high amount of habitat) show a monotonic decrease in persistence with increasing fragmentation (Fig. 4b).

Parasitation rates decreased with fragmentation and decreased with patch distance for a given fragmentation (Fig. 5). The decrease in parasitation rates with fragmentation is related to an increase of both the mean and the variability of host outbreak duration (Fig. 6). When patch size and patch distance were held constant, increasing habitat amount did not affect parasitation rates (not shown here).

\section{DISCUSSION}

Empirical investigation of how landscape structure affects biocontrol is far from trivial because detection of causal relationships in complex dynamical systems is very difficult and the description of landscape features is often equivocal. We therefore used a conceptually simple spatially explicit simulation model to disentangle the influences of the amount of suitable habitat within a landscape together with the habitat's fragmentation and isolation on biocontrol. We

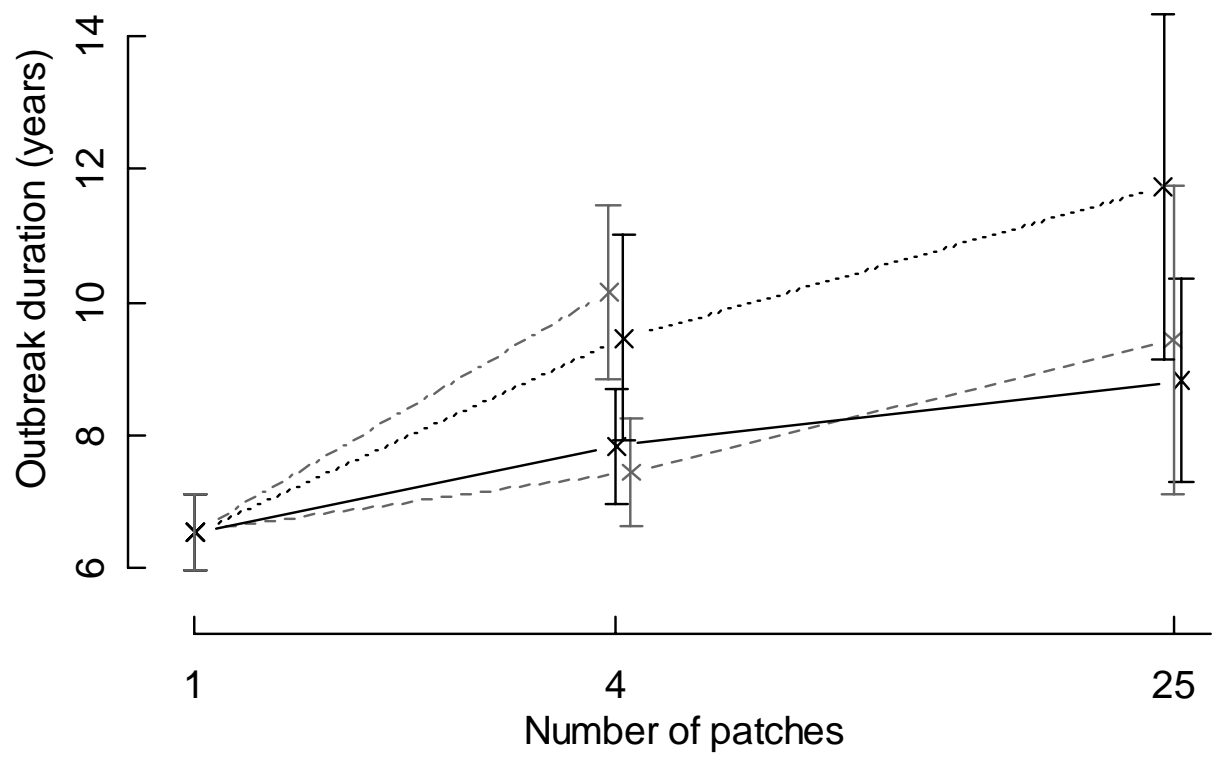

Fig. (6). Host outbreak duration increases with the number of patches in both habitat amount scenarios (exemplified here for low habitat amount). Solid line: patch distance $=5$ cells; dashed line: patch distance $=10$ cells; dotted line: patch distance $=20$ cells; dashed-dotted line: patch distance $=30$ cells; error bars show the standard deviation for ten simulation runs. Points have been jittered along the $\mathrm{x}$-axis to better distinguish between different error bars. 
focused on two widely used biocontrol measures: parasitoid persistence and parasitation rate, and varied the overall size, fragmentation, and mutual distance of habitat patches in a matrix of unsuitable habitat.

We found that the amount of habitat in a landscape modulates the effect of fragmentation on parasitoid persistence. Parasitation rate, on the other hand decreased with fragmentation regardless of the habitat amount in a landscape. Consequently, the effect of fragmentation and isolation on the performance of biocontrol as an ecosystem service hinges on whether the focus is on persistence or parasitation.

Our findings resolve the contradicting results of previous empirical studies which occasionally found either an increase or a decrease in the performance of host-parasitoid interactions with increasing spatial heterogeneity (see Introduction), making clear that the effect of additional habitat fragmentation depends on the original fragmentation level and on total habitat amount. However, parasitation rates decreased with increasing fragmentation, even though, if habitat was scarce, persistence at low fragmentation levels increased under the same conditions. Thus, persistence and parasitation rates respond differently to fragmentation if habitat is scarce but they respond similarly if habitat is abundant.

Persistence of parasitoid populations and parasitation rate are measures often applied in theoretical and field studies, respectively. Each of them reveals important properties of biocontrol, namely reliability and effectiveness, respectively, and therefore we used both measures in our model analysis. In the following, we will discuss the mechanisms leading to the landscape effects on the two measures separately.

Persistence of the parasitoid populations in a single patch was zero for small patch sizes and then increased abruptly with patch area (Fig. 3). This increase in parasitoid persistence with patch size was also found in the field (Cronin 2004) and can be explained by the spatial structure that the oscillating host-parasitoid populations develop in a single patch. In this case, a threshold area is needed to sustain the typical spatial wave-like or chaotic pattern. Population peaks and breakdowns coexist in space and time within the habitat patch and, consequently, persistence is high. However, if the patch area is too small, the wave-like pattern breaks down and parasitoid populations (and sometimes, synchronously, also host populations) become extinct (Hassell et al. 1993). As the scale of the spatial pattern depends on the dispersal abilities of hosts and parasitoids (Hassell 2000), the basic condition of such a mechanism is that dispersal is local compared to the area of the single habitat patch. A good overview of the effects of landscape structure on the spatiotemporal dynamical patterns of host-parasitoid systems is given by Hirzel et al. (2007).

In general, agricultural management programs aim at increasing biological control by increasing habitat availability for natural antagonists; they have shown some success in terms of increased antagonist abundances (Kielty, AllenWilliams \& Underwood 1992; Nentwig 2000). Based on our results for a single patch (Fig. 3), such measures can only be successful if a minimum amount of habitat can be provided. Management programs are often more limited by the amount of habitat that can be provided than by the spatial arrangement of this habitat in the landscape.

Our fragmentation experiments show that the spatial landscape arrangement should be considered in agricultural management because in many cases the available habitat area could be used more effectively by adjusting habitat fragmentation and isolation. If habitat is scarce, parasitoid persistence in the landscape is highest for intermediate fragmentation and isolation levels. This pattern can be explained by the tradeoff between high spatial synchrony of host-parasitoid oscillations at low fragmentation levels, and colonization limitation at high fragmentation levels. At low fragmentation the oscillatory dynamics of the interaction drives the whole system to a synchronized breakdown (Heino et al. 1997; Bjornstad, Ims \& Lambin 1999). At intermediate fragmentation levels, metapopulation dynamics (Levins 1969; Hanski \& Gilpin 1997) can develop and increase the persistence of the parasitoid population (Hirzel et al. 2007). These findings correspond to experimental results of Holyoak (1996) and modeling experiments of Nachman (1987) and Reeve (1988) which suggested highest persistence of a predator-prey metapopulation at intermediate dispersal.

However, by including within-patch local dynamics we could in addition show that maximum persistence at intermediate fragmentation can only be expected if the total habitat amount is low. If single habitat patches are large enough, the within-patch heterogeneity of local dynamics is sufficiently high to ensure high local persistence and metapopulation persistence decreases with fragmentation. This shows that consideration of details of the spatial withinpatch dynamics in combination with metapopulation dynamics (see e.g. Taylor (1991)) depending on elements of the landscape structure (number and isolation of fragments) can be essential when assessing the regional persistence of species interactions and can provide additional insights.

Unfortunately, persistence at the landscape level is very difficult to assess in the field and is virtually uninvestigated. Assuming that the loss of species diversity reflects lower species persistence, the study of Tscharntke et al. (2002) supports our result that parasitoid persistence may be better at intermediate levels of fragmentation compared to low fragmentation.

Parasitation rates consistently decreased with fragmentation and isolation, regardless of how much habitat was available. This negative effect of fragmentation on parasitation rates, or parasitoid species loss, is commonly observed in the field and interpreted as a result of the poor dispersal abilities of the parasitoid compared to the host (Tscharntke et al. 2005). However, we deliberately excluded this explanation by assuming that both host and parasitoid have the same dispersal ability. We observed the decrease in parasitation rate even under this assumption.

Although the dispersal of both hosts and parasitoids is hindered by increasing fragmentation and isolation, this effect is much stronger for the parasitoid. This is due to the fact that the parasitoid depends on a more ephemeral resource (host) than the host (habitat). Correspondingly, parasitoid colonization of habitat patches has been shown to 
depend on both isolation from other parasitoid populations and on the size of the host population (van Nouhuys \& Hanski 1999). With increasing fragmentation, the disadvantage of the parasitoid increasingly leads to the decoupling of the host population from the control of the parasitoid, which results in prolonged host outbreak duration and decreased average parasitation rates (Figs. 5 and 6). In such a situation, the parasitoid population perceives the host populations as a dynamic landscape (in contrast to the static habitat patches perceived by the host), which is known to lower metapopulation persistence, abundance, and occupancy (e.g. Johst, Brandl \& Eber 2002).

Thus, our modeling experiments confirm the findings of several field studies, that increasing fragmentation and isolation can decrease parasitation rates (Kruess \& Tscharntke 1994), increase prey outbreak duration (Kareiva 1987) and reduce prey tracking on a certain scale (With et al. 2002). It also reveals that the basic mechanism underlying their observations may be neither the difference in dispersal abilities of host and parasitoid nor the predator searching behavior interacting with landscape features but the decoupling of the population dynamics of pest and antagonist due to habitat structure.

Our results are qualitatively robust with regard to moderate differences in the host and parasitoid dispersal abilities and in reproduction parameters (data not shown), and presumably for oscillatory host-parasitoid and predatorprey interactions in general. Nevertheless, the quantitative effect of fragmentation and isolation on parasitation and persistence depends on several factors affecting spatiotemporal dynamics. Clearly, the local behavior of the interaction influences the quantitative effect of fragmentation and isolation on biocontrol by altering the patch extinction risk. Therefore, the detailed functional form of parasitation (e.g. negative binomial distribution (Hastings \& Godfray 1999)) will affect the quantitative scaling of the fragmentation effects. Another crucial factor for the quantification of the fragmentation effects is dispersal (Holyoak \& Lawler 1996; Earn, Levin \& Rohani 2000). The mean dispersal distances of hosts and parasitoids, their differences as well as the particular dispersal behavior will influence patch extinction and colonization probabilities. For example, density-dependent dispersal in contrast to the densityindependent dispersal implemented in our model might affect synchronization, i.e. "waves" of local populations in a similar state, and therefore our main results. However, it has been found that the synchronizing potential of density-independent dispersal in metapopulations is only slightly higher than that of density-dependent dispersal (Münkemüller and Johst 2008). Thus, the expected differences should be low. Moreover, a main condition for the wave-like pattern is that dispersal is local, not global, and this condition would be maintained by the density dependence of dispersal. Nevertheless, quantitative predictions for specific systems must be based on detailed empirical studies of these dispersal parameters and of the attacking behavior of the parasitoid.

Of course, in natural environments there are additional, often complex, influences, which cannot easily be considered in a model addressing such basic questions as ours.
For instance, Dwyer et al. (2004) propose the influence of an additional generalist antagonist as an explanation for temporal variability of host outbreaks. This suggests that factors other than landscape fragmentation might produce results similar to our model outcome.

The inclusion of more habitat types might alter population dynamics (Wiegand et al. 2005). In agricultural landscapes, crop field habitats add complexity to the system, often exhibiting increased reproduction potential, decreased overwintering suitability, and increased attraction for host and parasitoid as compared with semi-natural habitats. Additionally, crop rotation may occur, which can disrupt life-cycles or interactions and increase dispersal and winter mortality. Thus, the influence of the interaction between various habitat types on the principal landscape effect found here remains to be investigated (Tscharntke \& Brandl 2004).

We developed a conceptually simple model which reveals likely mechanisms influencing the performance of biocontrol in fragmented landscapes. Our model suggests that landscape effects on conservation biocontrol can be found even without any specific active response of the organisms to the landscape features and without any significant differences in their dispersal abilities.

If semi-natural habitat is scarce, which is often the case in agricultural landscapes, we found that there might be a conflict between parasitoid conservation and parasitation rate, i.e., between reliability and effectiveness of conservation biocontrol. In this case management can optimize either parasitation rates, via habitat aggregation, or parasitoid persistence, via aggregation or fragmentation depending on the original conditions. Only if the landscape contains enough habitat is there no conflict: in this case the habitat should be as clumped as possible in order to enhance conservation biocontrol at a landscape level.

\section{ACKNOWLEDGEMENTS}

We would like to thank the German Federal Environmental Foundation (DBU) for funding, and Carsten Thies and the BIOPLEX project group for discussions and inspiration. We owe special thanks to Wolfgang Köhler for providing good working conditions, funding and infrastructure for Kerstin Wiegand and Ute Visser at the Department of Biometry and Population Genetics, Interdisciplinary Research Centre for Environmental Protection (IFZ), Giessen, Germany.

\section{SUPPLEMENTARY MATERIAL}

Supplementary material is available on the publisher's Web site along with the published article.

\section{REFERENCES}

Barbosa, P (1998) Conservation biological control. Academic Press, San Diego, London, Boston, New York, Sydney, Tokyo, Toronto.

Bascompte, J, Possingham, H \& Roughgarden, J (2002) Patchy populations in stochastic environments: Critical number of patches for persistence. American Naturalist, 159, 128-137. 
Beddington, JR, Free, CA \& Lawton, JH (1978) Characteristics of successful natural enemies in models of biological control of insect pests. Nature, 273, 513-519.

Bellows, TS (1981) The descriptive properties of some models for density dependence. Journal of Animal Ecology, 50, 139-156.

Bjornstad, ON, Ims, RA \& Lambin, X (1999) Spatial population dynamics: analyzing patterns and processes of population synchrony. Trends in Ecology \& Evolution, 14, 427-432.

Blasius, B, Huppert, A \& Stone, L (1999) Complex dynamics and phase synchronization in spatially extended ecological systems. Nature, 399, 354-359.

Bolker, B \& Grenfell, B (1995) Space, persistence and dynamics of measles epidemics. Philosophical Transactions of the Royal Society London $B, 348,309-320$.

Bonsall, MB, French, DR \& Hassell, MP (2002) Metapopulation structures affect persistence of predator-prey interactions. Journal of Animal Ecology, 71, 1075-1084.

Börjesdotter, D (2000) Barbarea verna and Barbarea vulgaris as host plants for the pollen beetle (Meligethes aeneus). Journal of Agricultural Science, 134, 213-220.

Cardinale, BJ, Harvey, CT, Gross, K \& Ives, AR (2003) Biodiversity and biocontrol: emergent impacts of a multi-enemy assemblage on pest suppression and crop yield in an agroecosystem. Ecology Letters, 6, $857-865$.

Cronin, JT (2004) Host-parasitoid extinction and colonization in a fragmented prairie landscape. Oecologia, 139, 503-514.

Cronin, JT \& Reeve, JD (2005) Host-parasitoid spatial ecology: a plea for a landscape-level synthesis. Proceedings of the Royal Society London $B, 272,2225-2235$.

Daebeler, F, Seidel, D \& Michel, H-J (1990) Die Fruchtfolge beim Winterraps - eine wichtige Voraussetzung für gesunde Bestände II. Tierische Schaderreger. Feldwirtschaft, 31, 331-333.

De Roos, AM, McCauly, E \& Wilson, WG (1991) Mobility versus densitylimited predator-prey dynamics on different spatial scales. Proceedings of the Royal Society London B, 246, 117-122.

Dwyer, G, Dushoff, J \& Yee, SH (2004) The combined effects of pathogens and predators on insect outbreaks. Nature, 430, 341-345.

Earn, DJ, Levin, SA \& Rohani, P (2000) Coherence and conservation. Science, 290, 1360-1364.

Eber, S \& Brandl, R (1994) Ecological and genetic spatial patterns of Urophora cardui (Diptera: Tephritidae) as evidence for population structure and biogeographical processes. Journal of Animal Ecology, 63, 187-199.

Fritzsche, R (1956) Beeinflussung der Populationsdichte verschiedener Meligethes-Arten von gleichen Wirtspflanzen durch Parasiten. Bericht über die Hundertjahrfeier der deutschen Entomologischen Gesellschaft Berlin, Berlin: Akademie-Verlag.

Hanski, I \& Gilpin, ME, (1997) Metapopulation biology. Ecology, genetics, and evolution. San Diego, London: Academic Press.

Hassell, MP (2000) Host-parasitoid population dynamics. Journal of Animal Ecology, 69, 543-566.

Hassell, MP, Godfray, HC \& Comins, HN (1993) Effects of global change on the dynamics of insect host-parasitoid interactions. In: Kareiva, PM, Kingsolver, JG \& Huey, RB (Eds) Biotic Interaction and global change Sinauer Ass: Sunderland, Mass, pp. 402-423.

Hastings, A \& Godfray, HC (1999) Learning, host fidelity, and the stability of host-parasitoid communities. American Naturalist, 153, 295301.

Hawkins, BA \& Cornell, HV (1994) Maximum parasitism rates and successful biological-control. Science, 266, 1886.

Heino, M, Kaitala, V, Ranta, E \& Lindström, J (1997) Synchronous dynamics and rates of extinction in spatially structured populations. Proceedings of the Royal Society B, 264, 481-486.

Hirzel, AH, Nisbet, RM \& Murdoch,WW (2007) Host-parasitoid spatial dynamics in heterogeneous landscapes. Oikos, 116, 2082-2096.

Hokkanen, H, Husberg, G-B \& Söderblom, M (1988) Natural enemy conservation for the integrated control of the rape blossom beetle Meligethes aeneus F. Annales Agriculturae Fenniae, 27, 281-294.

Hokkanen, H (2000) The making of a pest: recruitment of Meligethes aeneus onto oilseed Brassicas. Entomologia Experimentalis et Applicata, 95, 141-149.

Holyoak, M \& Lawler, SP (1996) The role of dispersal in predator-prey metapopulation dynamics. Journal of Animal Ecology, 65, 640652.
Huffaker, CB (1958) Experimental studies of predation: Dispersal factors and predator-prey oscillation. Hilgardia, 27, 343-383.

Johst, K, Brandl, R \& Eber, S (2002) Metapopulation persistence in dynamic landscapes: the role of dispersal distance. Oikos, 98, 263270 .

Kareiva, P (1987) Habitat fragmentation and the stability of predator-prey interaction. Nature, 326, 388-390.

Kielty, JP, Allen-Williams, LJ \& Underwood, N (1992) The effects of setaside field margins on the distribution and biocontrol potential of polyphagous predatory arthropods in arable crops. In Clarke, J (Ed) Set-aside. BCPC, Farnham, pp. 169-174.

Kruess, A \& Tscharntke, T (1994) Habitat fragmentation, species loss and biological control. Science, 264, 1581-1584.

Landis, DA, Wratten, SD \& Gurr, GM (2000) Habitat management to conserve natural enemies of arthropod pests in agriculture. Annual Review of Entomology, 45, 175-201.

Levins, R (1969) Some demographic and genetic consequences of environmental heterogeneity for biological control. Bulletin of the Entomological Society of America, 15, 237-240.

Moilanen, A \& Hanski, I (1995) Habitat destruction and coexistence of competitors in a spatially realistic metapopulation model. Journal of Animal Ecology, 64, 141-144.

Münkemüller, T \& Johst, K (2008) Spatial synchrony through densityindependent versus density-dependent dispersal. Journal of Biological Dynamics, 2, 31-39.

Nachman, G (1987) Systems-Analysis of acarine predator prey interactions .2. the role of spatial processes in system stability. Journal of Animal Ecology, 56, 267-281.

Nentwig, W (2000) Streifenförmige ökologische Ausgleichsflächen in der Kulturlandschaft - Ackerkrautstreifen, Buntbrache, Feldränder. Verlag Agrarökologie, Bern: Hannover.

Nilsson, C (1989) The pollen beetle (Meligethes aeneus F.) in winter and spring rape at Alnarp1976-1978 II. Oviposition. Växtskyddsnotiser, $52,139-144$.

Reeve, JD (1988) Environmental variability, migration and persistence in host- parasitoid systems. American Naturalist, 132, 810-836.

Ryall, KL \& Fahrig, L (2006) Response of predators to loss and fragmentation of prey habitat: A review of theory. Ecology, 87, 1086-1093.

Sala, OE, Chapin, FS, Armesto, JJ, Berlow, E, Bloomfield, J, Dirzo, R, Huber-Sanwald, E, Huenneke, LF, Jackson, RB, Kinzig, A, Leemans, R, Lodge, DM, Mooney, HA, Oesterheld, M, Leroy Poff, N, Sykes, MT, Walker, BH, Walker, M \& Wall, DH (2000) Global biodiversity scenarios for the year 2100. Science, 287, 1770-1774.

Sherratt, JA, Lambin, X \& Sherratt, TN (2003) The effects of the size and shape of landscape features on the formation of traveling waves in cyclic populations. American Naturalist, 162, 503-513.

Taylor, AD (1991) Studying metapopulation effects in predator-prey systems. Biological Journal of the Linnean Society, 42, 305-323.

Thies, C, Steffan-Dewenter, I \& Tscharntke, T (2003) Effects of landscape context on herbivory and parasitism at different spatial scales. Oikos, 101, 18-25.

Thies, C \& Tscharntke, T (1999) Landscape structure and biological control in agroecosystems. Science, 285, 893-895.

Tilman, D, Lehman, CL \& Y in, C (1997) Habitat destruction, dispersal, and deterministic extinction in competitive communities. American Naturalist, 149, 407-435.

Tscharntke, T \& Brandl, R (2004) Plant-insect interactions in fragmented landscapes. Annual Review of Entomology, 49, 405-430.

Tscharntke, T, Klein, AM, Kruess, A, Steffan-Dewenter, I \& Thies, C (2005) Landscape perspectives on agricultural intensification and biodiversity - ecosystem service management. Ecology Letters, 8, 857-874.

Tscharntke, T, Steffan-Dewenter, I, Kruess, A \& Thies, C (2002) Contribution of small habitat fragments to conservation of insect communities of grassland-cropland landscapes. Ecological Applications, 12, 354-363.

van Nouhuys, S \& Hanski, I (1999) Host diet affects extinctions and colonizations in a parasitoid metapopulation. Journal of Animal Ecology, 68, 1248-1258.

Wiegand, T, Revilla, E \& Moloney, K (2005) Effects of habitat loss and fragmentation on population dynamics. Conservation Biology, 19, 108-121. 
With, KA, Pavuk, DM, Worchuk, JL, Oates, RK \& Fisher, JL (2002b) Threshold effects of landscape structure on biological control in

agroecosystems. Ecological Applications, 12, 52-65.

Received: January 09, 2009

Revised: February 12, 2009

Accepted: February 24, 2009

(C) Visser et al.; Licensee Bentham Open.

This is an open access article licensed under the terms of the Creative Commons Attribution Non-Commercial License (http://creativecommons.org/licenses/by$\mathrm{nc} / 3.0 /$ ), which permits unrestricted, non-commercial use, distribution \& reproduction in any medium, provided the work is properly cited. 